University of Nebraska - Lincoln

DigitalCommons@University of Nebraska - Lincoln

2015

\title{
Using Visual Scene Displays as Communication Support Options for People with Chronic, Severe Aphasia: A Summary of AAC Research and Future Research Directions
}

\author{
David R. Beukelman \\ University of Nebraska-Lincoln, dbeukelman1@unl.edu \\ Karen Hux \\ University of Nebraska-Lincoln, khux1@unl.edu \\ Aimee R. Dietz \\ University of Cincinnati, aimee.dietz@uc.edu \\ Miechelle L. McKelvey \\ University of Nebraska-Kearney, mckelveyml@unk.edu \\ Kristy S.E. Weissling \\ University of Nebraska - Lincoln, kristy.weissling@unl.edu \\ Follow this and additional works at: https://digitalcommons.unl.edu/specedfacpub \\ Part of the Analytical, Diagnostic and Therapeutic Techniques and Equipment Commons, Special \\ Education and Teaching Commons, Speech and Hearing Science Commons, and the Speech Pathology \\ and Audiology Commons
}

Beukelman, David R.; Hux, Karen; Dietz, Aimee R.; McKelvey, Miechelle L.; and Weissling, Kristy S.E., "Using Visual Scene Displays as Communication Support Options for People with Chronic, Severe Aphasia: A Summary of AAC Research and Future Research Directions" (2015). Special Education and Communication Disorders Faculty Publications. 151.

https://digitalcommons.unl.edu/specedfacpub/151

This Article is brought to you for free and open access by the Department of Special Education and Communication Disorders at DigitalCommons@University of Nebraska - Lincoln. It has been accepted for inclusion in Special Education and Communication Disorders Faculty Publications by an authorized administrator of DigitalCommons@University of Nebraska - Lincoln. 
Published in Augmentative and Alternative Communication 31:3 (2015), pp 234-245. doi: 10.3109/07434618.2015.1052152

Copyright ( 2015 International Society for Augmentative and Alternative Communication; published by Taylor \&

Francis. Used by permission.

Submitted 3 September 2014; revised 30 April 2015; accepted 7 May 2015.

This paper is part of the Special 30th Anniversary of Augmentative and Alternative Communication Series.

\title{
Using Visual Scene Displays as Communication Support Options for People with Chronic, Severe Aphasia: A Summary of AAC Research and Future Research Directions
}

\author{
David R. Beukelman, ${ }^{1,2}$ Karen Hux, ${ }^{2}$ Aimee Dietz, ${ }^{3}$ Miechelle McKelvey, ${ }^{4}$ and Kristy Weissling ${ }^{2}$ \\ 1 Institute for Rehabilitation Research and Engineering, Madonna Rehabilitation Hospital and University of Nebraska-Lincoln \\ 2 Department of Special Education and Communication Disorders, University of Nebraska-Lincoln \\ 3 Department of Communication Sciences and Disorders, University of Cincinnati \\ 4 Department of Communication Disorders, University of Nebraska-Kearney
}

Corresponding author - David R. Beukelman, PO Box 830732, 202 Barkley Memorial Center, University of Nebraska, Lincoln, Nebraska, USA. Tel: 402-472-5463, email dbeukelman1@unl.edu

\begin{abstract}
Research about the effectiveness of communicative supports and advances in photographic technology has prompted changes in the way speech-language pathologists design and implement interventions for people with aphasia. The purpose of this paper is to describe the use of photographic images as a basis for developing communication supports for people with chronic aphasia secondary to sudden-onset events due to cerebrovascular accidents (strokes). Topics include the evolution of AAC-based supports as they relate to people with aphasia, the development and key features of visual scene displays (VSDs), and future directions concerning the incorporation of photographs into communication supports for people with chronic and severe aphasia.
\end{abstract}

Keywords: Communication, Aphasia, Photographs, Visual scene displays, Augmentative and alternative communication

\section{Introduction}

Intervention to treat the language processing challenges displayed by people with aphasia has been a routine practice since the 1950s when Schuell and her colleagues developed the Language Stimulation approach (Schuell, Jenkins, \& Jimenez-Pabon, 1964). The basic aim of this and other early aphasia intervention procedures was to restore language functions (Brookshire, 2003; Chapey, 2001; Duffy \& Coelho, 2001). Evidence of the effectiveness of such approaches - especially during the acute stages of recovery - appear in the extant literature (Holland, Fromm, DeRuyter, \& Stein, 1996; Horner, Loverso, \& Gonzalez-Rothi, 1994; Poeck, Huber, \& Williams, 1989; Robey, 1998); however, over the intervening years, aphasiologists increasingly became aware that these treatment approaches in isolation were insufficient to eliminate the language challenges of a substantial proportion of people with aphasia (Helm-Estabrooks, 1984; LaPointe, 2011). Specifically, between 40 and $60 \%$ of individuals with aphasia live their lives with aphasia as a chronic condition (Laska, Hellblom, Murray, Kahan, \& Von Arbin, 2001; Pedersen, Vinter, \& Olsen, 2004). The persistent language processing challenges displayed by people with chronic aphasia prevent them from participating fully during daily communicative interactions (Brennan, Worrall, \& McKenna, 2005; Garrett \& Lasker, 2005; Holland \& Beeson, 1993; Hux, Weissling, \& Wallace, 2008; LaPointe, 2005; Lasker, 1999; Lasker, LaPointe, \& Kodras, 2005; Van de Sandt-Koenderman, 2004).

Clinicians began introducing augmentative and alternative communication (AAC) supports in the form of simple communication boards as early as the 1980s, in an effort to help people with aphasia compensate for persistent language deficits. However, the primary aphasia textbooks available at that time (e.g., Brookshire, 1978; Collins, 1986; Darley, 1982; Goodglass \& Blumstein, 1973; Howard \& Hatfield, 1987; Jenkins, Jimenez- Pabon, Shaw, \& Sefer, 1975; Schuell et al., 1964) did not contain chapters about AAC interventions or communication supports; in fact, most of these books failed to even mention AAC or communication supports as intervention options. Not until 4 years had elapsed following the introduction of the Augmentative and Alternative Communication journal did an article (i.e., Beukelman \& Garrett, 1988) about AAC-based communication supports for people with aphasia appear in the professional literature. Even this paper, however, did not provide treatment data or 
case information; instead it focused on presenting an aphasia intervention framework incorporating AAC principles. The following year, Garrett, Beukelman, and Low-Morrow (1989) detailed the communication supports developed for a man with severe, chronic aphasia. Only since then have professionals from the aphasia and AAC fields routinely investigated and documented the effectiveness of teaching people with aphasia and their communication partners to use a range of communication supports.

Simmons-Mackie, King, and Beukelman (2013) define communication supports for people with aphasia as anything that supplements residual speech and language to improve access to or participation in communication, events, or activities. Communication supports include tools, strategies, techniques, and therapy procedures that facilitate successful communication between people with aphasia and their communication partners. In most ways, the terms communication supports and AAC strategies are similar; however, as used in the aphasia field, communication supports is probably more inclusive.

Communication supports in the context of aphasia intervention include materials and strategies that incorporate remnants (e.g., ticket stubs, receipts, performance programs, and newspaper articles), photographs, drawings, gestures, written words, communication books, boards, speech-generating devices, and mobile technologies with AAC applications to facilitate communicative competence as well as linguistic comprehension and expression. Combining these communication supports with more traditional restoration-based interventions is becoming increasingly common as speech-language pathologists, people with aphasia, and friends and family of people with aphasia recognize the benefits of introducing AAC-based options early in the recovery process. For this to become routine, however, people must realize that (a) restoration and compensation approaches need not be mutually exclusive, and (b) adoption of a compensatory strategy does not imply that hope has been abandoned for further recovery of natural speech and language comprehension and production (Weissling \& Prentice, 2010).

A combined restoration-compensation approach allows for adjustment of a person's relative dependence on natural speech and communication supports in accordance with the extent of his or her recovery, the familiarity and skill of a listener, and the complexity of the communication situation. By having a variety of strategies and techniques from which to choose when confronted with communication opportunities and breakdowns, people with aphasia have an increased likelihood of comprehending and expressing multiple intents to multiple people across multiple settings. This increased communicative independence and autonomy can potentially improve both the quantity and quality of social interactions available to people with chronic aphasia.

The use of communication support strategies and techniques can help people with persistent and unmet communication needs, resulting from aphasia, compensate for residual deficits (Garrett \& Lasker, 2013; SimmonsMackie et al., 2013). Extant evidence confirms that some people with severe aphasia can use AAC strategies to facilitate performance of specific communicative acts such as answering the phone, calling for help, ordering in restaurants or stores, giving speeches, saying prayers, engaging in highly scripted conversations, and facilitating word retrieval (Jackson-Waite, Robson, \& Pring, 2003; Lasker \& Bedrosian, 2001; Lasker \& Beukelman, 1999). Successful use of these strategies often requires the involvement of well-trained communication partners such as spouses, adult children, or committed friends, rather than untrained or unfamiliar people in the social or service-provision network of the person with aphasia. As such, extensive efforts have focused on training frequent communication partners about the use of communication supports (Hinckley, Douglas, Goff, \& Nakano, 2013). The result of this training may be solely to support interactions between the individual with aphasia and a single communication partner; however, for some, the training extends beyond that dyad, and the communication partner supports the individual with aphasia as he or she engages with others in the social community. Regardless, access to well-trained partners can be unpredictable because of changes in employment, interpersonal relationships (e.g., divorce, separation, or disengagement), or health issues. Because of this, a need exists to prepare people with chronic aphasia to be as independent as possible in their communicative interactions.

\section{Visual Scene Displays}

Clinicians have developed a range of communication support strategies to supplement restorative intervention and minimize the devastating effects of sudden-onset, severe, chronic, aphasia on people's communicative efforts (e.g., Garrett \& Lasker, 2013; King, 2013; King, Alarcon, \& Rogers, 2007; Lasker, Garrett, \& Fox, 2007). Historically, symbols (e.g., icons, printed words/phrases, or photographs) serving as communication supports were organized into grid formats in which they occupied individual spaces placed at regular intervals on the display (Beukelman, Yorkston, \& Dowden, 1985; Garrett, 1993; Garrett \& Huth, 2002; Garrett \& Lasker, 2005; Ho, Weiss, Garrett, \& Lloyd, 2005; King, 2013; Lyon, 1992, 1995, 1998; Lyon \& HelmEstabrooks, 1987). More recently, clinicians have implemented visual scene displays (VSDs) - combinations of high-context images and associated written words, phrases, or sentences that establish a shared communication space - to support the communicative interactions of people with aphasia and their conversational partners (Dietz, McKelvey, \& Beukelman, 2006). Figure 1 provides an example of a VSD that might serve to support a person with aphasia when talking with others about carving a pumpkin with his granddaughter. Over the past decade, we have monitored people with chronic, severe aphasia using various 


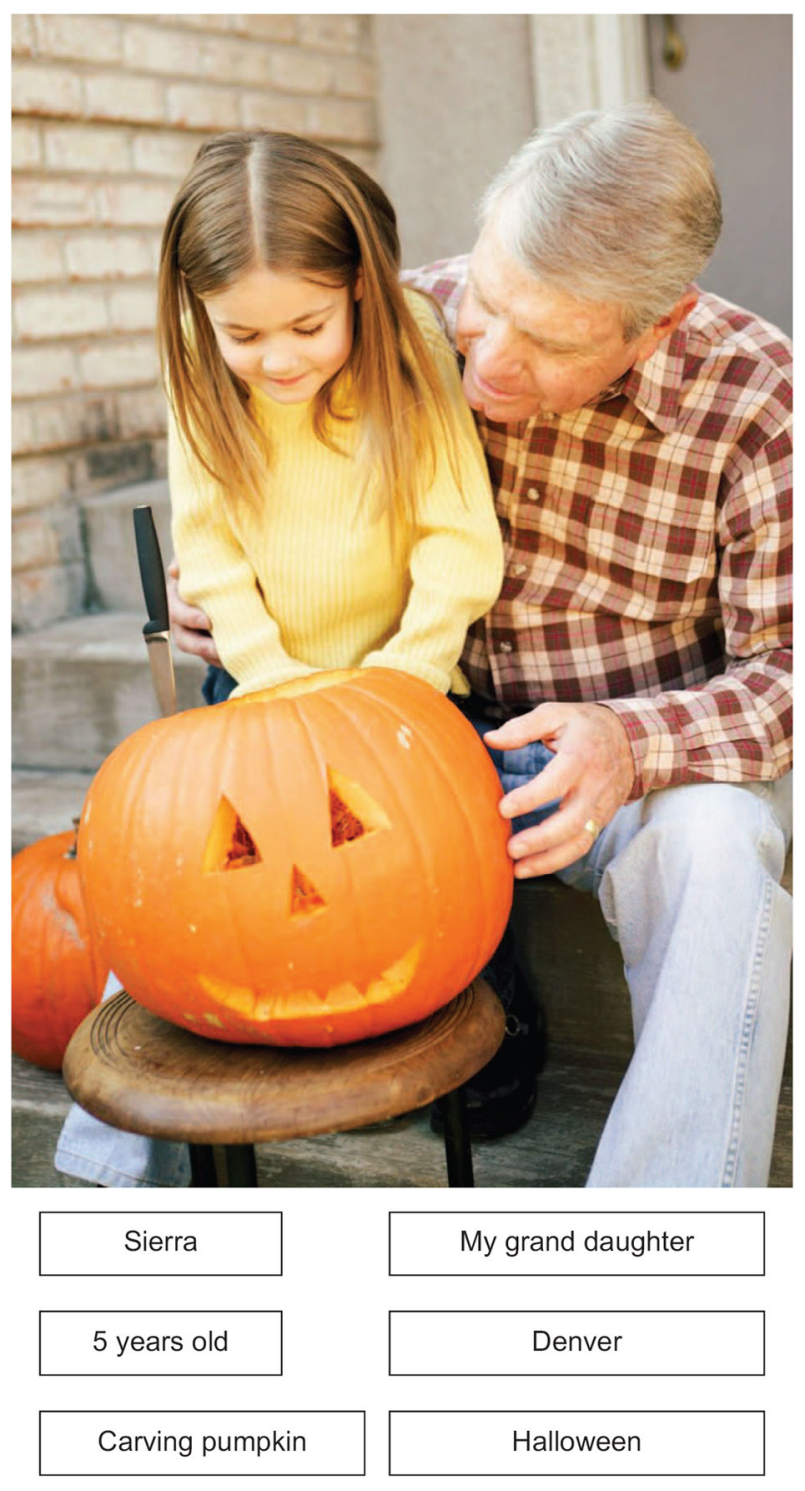

Figure 1. Visual scene display of a man carving a pumpkin with his granddaughter.

types of VSDs during field trials, research projects, and interventions. From these experiences, we have learned that personally relevant, high-context photographs, textboxes, and speak buttons seem to be key elements of VSD interfaces for people with aphasia.

\section{Contextualized Photographs}

Highly contextualized photographs have several important features that make them desirable for use with people with aphasia (Dietz et al., 2006; Hux, Buechter, Wallace, \& Weissling, 2010; McKelvey, Hux, Dietz, \& Beukelman, 2010). Alternately referred to as contextually rich or high-context images, these photographs "depict situations, places, or experiences in ways that clearly represent relationships and interactions among important people or objects" (Hux et al., 2010, p. 644). More specifically, they provide information about the environment in which an event or situation occurs, provide a means of identifying people or objects relevant to a person with aphasia, and depict an activity associated with an event as well as provide information to establish or clarify engagement relationships among the people and objects depicted (Beukelman, Dietz, Hux, McKelvey, \& Weissling, 2007; Wallace, Dietz, Hux, \& Weissling, 2012). Even a single high-context photograph such as that appearing in Figure 1 can establish the context for a conversational interaction and provide a person with aphasia and potential communication partners with information to support multiple communication exchanges (Hux et al., 2010).

The inclusion of high-context photographs that have personal relevance to a person with aphasia seems to be helpful in supporting communicative interactions. Personally relevant photographs are ones to which a person has a direct connection, that is, the individual either appears in the image or is highly familiar with the depicted people and/or setting (McKelvey et al., 2010). Through case studies, researchers have found that people with chronic aphasia are more likely to reference personally relevant photographs than non-personally relevant photographs or line drawings depicting comparable content when relaying narratives about salient life events (Dietz, Weissling, Griffith, McKelvey, \& Macke, 2014; Griffith, Dietz, \& Weissling, 2014). In fact, nonpersonally relevant photographs were sometimes detrimental to communicative interactions, because they prompted the participants with aphasia to make off-topic comments in an attempt to tell listeners that the image did not depict the actual event about which they were talking (Dietz, Weissling et al., 2014).

To understand how people process photographs, researchers have used eye tracking research technology to determine the parts of visual scenes that attract the visual focus of people with aphasia as well as adults without neurological deficits (Thiessen, 2013; Thiessen, Beukelman, Ullman, \& Longenecker, 2014; Wilkinson \& Light, 2011). Findings show that people in both participant groups allocate greater visual attention to a depicted object when the human figure appearing in the scene is touching and looking at the object rather than looking at the camera. Knowing that people both with and without aphasia perceive and respond to these task-engagement cues suggests important implications for creating visual scene displays to convey specific messages. For example, one man with aphasia restored antique automobiles as a hobby. In one photograph, both he and a car on which he was working are depicted, but the man is facing the camera rather than engaging with the car; another photograph captured him engaging with the antique car by polishing it. The latter photograph included naturally occurring task-engagement cues that supported communication about the man's current activity and also provided information about physical details of the automobile.

The inherent visual complexity of high-context photographs may raise concerns about how well people with sudden-onset aphasia can interpret them. Wallace, Hux, Brown, and Knollman-Porter (2014) explored this issue by comparing people with and without aphasia regarding the 
accuracy and speed with which they derived main action, background, and inferential information from high-context images. The researchers asked participants to view sets of four colored paintings (i.e., Norman Rockwell images) matched on various key features and then select the one that best matched the spoken sentences. Although the participants with aphasia were slower and less accurate than the participants without neurological impairment, their response patterns suggested they could derive substantial factual as well as inferential information from high-context images. Furthermore, this ability was evident despite the severity of some participants' aphasia as measured via standardized assessments.

Photographs that are not contextualized, such as portraits of individuals positioned in front of neutral backgrounds, contrast with high-context images in that they require a viewer to surmise information about relationships and events. Because no interaction or engagement occurs among depicted people and the environment, and the image typically displays limited, if any, information about the situation, place, or objects present, the central action or event associated with the photograph is not readily apparent. Photographs with minimal contextual information force a person with aphasia to generate additional content independently to explain the associated event and/or interpersonal relationships - an inherent challenge for people with aphasia. For communication partners, the challenge is speculating about possible scenarios that might relate to the photograph. As a result, low-context photographs are not likely to minimize communication struggles and breakdowns as effectively as high-context, personally relevant photographs; however more empirical evidence is necessary to understand the role of these image types in helping people with aphasia communicate.

\section{Text Boxes and Speak Buttons}

Text components of visual scene displays also seem to play key roles in supporting the communication of people with aphasia because they provide a means of relaying important and preferred content associated with one or more photographs. Based on the preferences, needs, and capabilities of a person with aphasia, this text can be single words, short phrases, or complete sentences. For example, the VSD in Figure 1 includes several single words (e.g., Denver, Halloween ) as well as short phrases (e.g., carving pumpkin, 5 years old ). In some cases, text is paired with speak buttons that, when activated, produce a spoken message via synthesized or digitized speech. Through case studies, researchers have found that people with aphasia report they benefit from having written messages as well as high-context photographs in VSDs (Dietz, Weissling et al., 2014; Griffith et al., 2014).

Preliminary observations from our field studies revealed several important issues relevant to the use of speak buttons by people with chronic, severe aphasia (Dietz et al.,
2006). First, these individuals prefer to have speak buttons in a distinct location rather than embedded within contextualized images. This may be because they like to point to particular feature(s) (i.e., a person or object) within an image or an individual word in a textbox, and they wish to do so without inadvertently activating speech output. Second, people with aphasia like to have the speech output match the associated written material, presumably because they are reluctant to activate speak buttons if they are uncertain about the message content. As one participant communicated to us through a multimodal exchange, "Pushing that button (without text present) is like opening your mouth to talk and not knowing what is going to come out!" A person with aphasia may feel unsure of the message that the speak button will produce unless the corresponding text is present. This phenomenon occurs even when people with aphasia have substantial reading comprehension deficits with decontextualized text; it appears to relate to their desire to speak appropriately (Dietz, McKelvey, Beukelman, Weissling, \& Hux, 2005; Dietz, Weissling et al., 2014; Griffith et al., 2014).

Relative to the use of speak buttons, we noted during our preliminary work with high-tech visual scene devices that voice-output clarity was another important consideration. Most people with severe aphasia experience some level of auditory comprehension deficit and therefore they experience difficulty understanding synthesized speech that is not of high quality. Furthermore, at least some of the communication partners of people with aphasia are elderly adults who have hearing limitations that may hinder their understanding of synthesized speech.

\section{Why VSDs are Helpful}

VSDs can support both intervention activities for people with chronic, severe aphasia and the communication interactions that these individuals have with others. This support may be because photographic images of personally relevant people, objects, and activities rely heavily on autobiographical memory and visuocognitive abilities rather than linguistic processing as the basis for message representation and AAC system navigation (Dietz et al., 2006). VSDs also provide a foundation for establishing a shared communication space between a person with aphasia and his or her communication partners, and they can provide a means of addressing pragmatic challenges exhibited by some people with aphasia when attempting to engage in conversational interactions.

\section{Autobiographical Memory and Retained Visuocognitive Abilities}

People with aphasia typically have preserved autobiographical memory and intellectual abilities that contrast with the severity of their linguistic processing challenges (McNeil, 1983). Further preserved functions may include 
facial recognition, visual-perceptual skills, and gestalt processing (Blake, 2005; Brookshire, 2003). Taken together, these preserved skills allow people with aphasia to recognize, process, and recall photographs of familiar people and events with relative ease even when their aphasia is severe and chronic (Fox \& Fried-Oken, 1996). Several investigators have documented communicative success using visuographic supports (e.g., photographs, souvenirs, maps, magazine, or newspaper articles) during interactions with people with aphasia (Fox \& Fried-Oken, 1996; Garrett \& Huth, 2002; Ho et al., 2005). VSDs appear to offer similar support by providing personal, visuographic, contextual information to clarify content and facilitate access to residual language abilities (Dietz, Hux, McKelvey, \& Beukelman, 2009; Dietz, Knollman-Porter, Hux, Toth, \& Brown, 2014; Dietz, Weissling et al., 2014; Griffith et al., 2014; McKelvey, Dietz, Hux, Weissling, \& Beukelman, 2007). Thus, VSDs may improve communicative effectiveness and, in turn, the social interactions of people with chronic, severe aphasia.

Although there seem to be many benefits of incorporating VSDs into low- and high-technology systems, traditional AAC layouts continue to be explored as viable options for people with aphasia as well (e.g., Koul, Corwin, \& Hayes, 2005; Koul, Corwin, Nigam, \& Oetzel, 2008; Koul \& Harding, 1998; Koul \& Lloyd, 1998). Historically, AAC systems have been organized into grid formats, in which symbols or icons occupy individual spaces placed at regular intervals. Such an organizational strategy requires that a person process the symbols individually and combine them to formulate messages. This type of organization mandates a high level of linguistic processing; that is, a person must discriminate and identify what each symbol represents and sequence it properly with other symbols to generate a message. Working memory is heavily taxed, because the person must hold a target word(s) in memory while locating the associated symbol(s) within an interface (Wilkinson \& Jagaroo, 2004). A recent study empirically documented that people without disabilities relied on phonological encoding to recall word lists via AAC systems that employed a semantic organization strategy (Dukhovny \& Soto, 2013); the data were less clear about whether people with cerebral palsy (who relied exclusively on AAC to communicate) also employed phonological encoding. However, people with aphasia may be more likely to rely on phonological encoding to learn words via AAC given that, prior to their strokes, they had intact language systems (Dietz, Weissling et al., 2014). If this is true, using grid-based symbol displays may require more extensive training for people with aphasia than systems that utilize personally relevant VSDs. This is because the use of grid-based symbol systems requires people to link together multiple symbols to construct a single sentence, thus taxing working memory more (Thistle \& Wilkinson, 2013; Wilkinson \& Jagaroo, 2004; Wilkinson, Light, \& Drager, 2012). This activity could overwhelm the already impaired working memory of people with aphasia (Dietz, Weissling et al., 2014).

AAC strategies utilizing visual scene displays provide an alternative means of processing the available information that seems to have greater automaticity than grid displays. Specifically, the visual processing of a high-context image allows for rapid comprehension of the overall meaning or "gist" of the depicted scenario (Wilkinson \& Jagaroo, 2004; Wilkinson et al., 2012). Associations and relations among people engaged with objects, places, and events are relatively transparent and require little or no linguistic interpretation or manipulation. Finally, photographs provide detailed visual information such as the physical features of people, objects, or scenery that are difficult for someone with language limitations to describe in detail. This detailed visual information can facilitate co-construction of messages with communication partners as well as provide a possible means of stimulating the semantic system through the recall of autobiographical memories and facilitation of word retrieval (Dietz, Weissling et al., 2014). Speakers without communication challenges use photographs for comparable reasons when they attempt to provide detailed information about the physical features of a person or experience (Light \& McNaughton, 2013). The evolving use of mobile technology to share life experiences during conversation may facilitate increased acceptance of AAC use by people with aphasia, especially when AAC strategies include references to photographic stimuli (Dietz, Weissling et al., 2014).

The symbolic processing and cognitive resource allocation deficits of people with aphasia make the generation and comprehension of novel utterances difficult (e.g., McNeil, 1983; Murray, 1999; Wright, Downey, Gravier, Love, \& Shapiro, 2007). As a result, people with aphasia struggle to formulate messages using symbols that have little implied relation or specific association with one another or with the actions, objects, or ideas they represent. However, many people with aphasia retain considerable ability to retrieve and organize information from visual representations such as contextualized photographs, maps, diagrams, or floor plans (Fox \& Fried-Oken, 1996; Ho et al., 2005). Because of this, employing high-context images as the primary mechanism for communication and AAC navigation may build upon the relatively intact cognitive and visuoperceptual abilities of people with aphasia as well as their extensive real-world and personal knowledge.

McKelvey and her colleagues conducted a study exploring the preferences and comprehension facilitation of personally relevant contextualized photographs, nonpersonally relevant contextualized photographs, and iconic images of eight people with moderate to profound chronic aphasia to determine the effect of using different types of visual stimuli as AAC support materials (McKelvey et al., 2010). The participants demonstrated significantly better word-to-photograph association when viewing personally relevant contextualized stimuli, and preferred these photographs to the 
other two types of stimulus images. Additionally, the data revealed a trend for faster response times when the participants with aphasia viewed personally relevant contextualized photographs rather than nonpersonally relevant contextualized photographs or iconic images.

People with aphasia seem to benefit from the use of personally relevant, contextualized photographs to support communication because of their extensive information base from life experiences before and after the onset of aphasia (i.e., world knowledge). However, expressive communication limitations and impaired categorical organization can make retrieving this information stored in an AAC device difficult. Our experiences suggest that many people with severe aphasia retrieve autobiographically stored information more efficiently than categorically stored information. For example, we worked with a man with chronic, severe aphasia who could not retrieve information about food and drink from the food category page in his AAC system; however, he could efficiently retrieve the information when it was stored in a cabin page. Apparently, he associated grilling - and thus, food and drink - for his family with the time spent at their cabin.

\section{Shared Communication Space for Message Co-construction}

Many people with chronic, severe aphasia do not achieve communication independence, that is, they often do not succeed in using natural speech, AAC technology, or a combination of the two to formulate and express a variety of messages independently to a variety of listeners. Rather, people with chronic, severe aphasia often rely on co-construction with a familiar, trained communication partner to formulate messages (Garrett \& Lasker, 2005; Hinckley et al., 2013; Kagan, 1998; Lasker \& Garrett, 2007; Lyon, 1995; Simmons-Mackie \& Schultz, 2004; Stuart, Lasker, \& Beukelman, 2000). As such, a key feature associated with using visual scene supports is the establishment of a shared communication space to allow for message co-construction. Specifically, the combination of high-context images and accompanying text of VSDs comprise the shared communication space and provide the background information and content a person with aphasia might otherwise struggle to convey. By referencing the provided pictorial, written, and auditory information, a communication partner can use VSDs in conjunction with the person with aphasia to facilitate increased comprehension and expression. The VSD serves as a platform for people with aphasia and their partners to build upon and discuss related topics as they engage in a communicative interaction.

Hux and her colleagues investigated the effect of using VSDs to create a shared communication space between a person with aphasia who had recovered only limited verbal expression and his unfamiliar partners (Hux et al., 2010). They found that access to the VSDs affected both members of the communication dyad. By evaluating the amount and quality of information conveyed during three experimental conditions - shared VSDs (i.e., both communication partners could view the visual scenes), nonshared VSDs (i.e., only the person with aphasia could view the visual scenes), and no VSDs - the researchers found that the shared visual scene condition yielded the most conversational turns, the greatest number of content units conveyed by the person with aphasia, and the greatest conceptual complexity of communication partner utterances. In addition, Likert-scale responses from the person with aphasia about perceived communicative ease and effectiveness indicated that information transfer, ease of conversational interaction, and partner understanding were best in the shared visual scene condition.

\section{Attention to Pragmatic Challenges}

AAC facilitators and communication partners can also incorporate features into VSDs to improve the quality of interactions between people with aphasia and communication partners. For example, during field trials, using color coding to differentiate various types of printed messages emerged as a potentially important feature for addressing pragmatic challenges that interfered with appropriate interactions between some people with aphasia and their communication partners (McKelvey et al., 2007). Specifically, field-trial data revealed that a subset of individuals with aphasia had difficulty interjecting questions into conversations that allowed partners to assume a portion of the communication load. These individuals with aphasia needed coaching on how and when to ask questions during communicative interactions supported by AAC technology. This challenge probably relates to the inherent difficulty some people with aphasia experience using question forms. As a result, when these individuals began using VSDs, they tended to retrieve and speak messages in sequential order with little or no regard for the situational context or the interjections of a communication partner. Color-coding to distinguish text and corresponding speak buttons relaying statements versus questions (combined with role-playing to practice turn-taking skills) facilitated achievement of more balanced interactions with communication partners (McKelvey et al., 2007).

Color-coding may also serve to address other types of pragmatic challenges interfering with a person's successful use of AAC devices incorporating VSDs. For example, some people with aphasia have difficulty discerning conversation starters from conversation closers. Simply selecting one color to signify text containing one type of message and another color to signify text containing the other type of message may provide a possible solution to this problem. However, practitioners need to exercise caution when applying color-coding schemes to VSDs. Although colorcoding may provide grouping cues to facilitate discrimination of various types of messages or functions, preliminary research by Wilkinson and Snell (2011) has shown 
that, although children benefit from groupings, they do not benefit when displays have color backgrounds rather than white backgrounds. It seems that the color backgrounds may be detrimental to image selection accuracy and efficiency by inadvertently drawing attention away from the main symbol content. Future research should focus on the effect of display color strategies on the performance of people with aphasia.

\section{Navigation Strategies}

Difficulty navigating low- and high-technology AAC systems has repeatedly emerged as a challenge for people with severe aphasia. For example, many people with aphasia who use communication books as support devices page through the books linearly when searching for appropriate content. They do not appear to have sufficient categorical capability to identify a desired topic when the book's organizational structure relies on groupings such as food, travel, family, health, and so on. As mentioned previously, AAC strategies developed for people with physical limitations traditionally use symbols or icons categorically organized into grids to represent content. This type of organization requires reliance on the use of isolated symbols or icons to navigate to multiple levels or pages within an AAC device or notebook. However, functional use of these organization and navigation strategies requires considerable cognitive-linguistic processing that typically exceeds the abilities of people with severe aphasia, or it requires a trained communication partner to monitor an interaction and provide the individual with aphasia with access to appropriate support materials.

A primary design specification goal when developing communication supports for people with aphasia is to create navigation strategies that are relatively transparent. This is important because it provides a means of assisting a person with aphasia in gaining greater communicative independence. Our research and case studies suggest three features that may be key to facilitating navigation: (a) the organization of content according to themes based on autobiographical episodic experiences, (b) the representation of these themes by "signature" photos or images that usually have high personal and contextual relevance, and (c) the use of a simple and consistent navigation strategy to access additional content within a theme. These principles appear to be important both for high- and low-technology AAC systems incorporating VSDs.

\section{Autobiographical Memories}

Episodic experiences result in the formation of autobiographical memories involving specific times, places, people, and events (Scott \& Schoenberg, 2011). When remembering an episodic experience, people recall the particular situation, such as their wedding day or the place they went yesterday, that resulted in the formation of a memory. Mesial temporal lobe structures, including the perirhinal and entorhinal cortices and the hippocampus are particularly important for encoding episodic memories (Schoenberg, Marsh, \& Lerner, 2011), and intact functioning of the right prefrontal cortex is necessary for retrieval of these memories (Scott \& Schoenberg, 2011). As such, brain damage associated with anoxia, traumatic brain injury, and certain types of dementia are frequent causes of impaired episodic memory (Scott \& Schoenberg, 2011); however, the focal, left perisylvian damage from which sudden-onset aphasia most often results does not typically involve structures crucial for forming, retaining, or retrieving these types of memories. Consequently, AAC systems that organize content according to an individual's personal autobiographical experiences can be effective for people with aphasia.

\section{Signature Photos}

Another helpful feature of high-tech AAC systems incorporating visual scenes and a theme navigation strategy is the use of signature photos relating to each available theme located in the same position throughout the AAC system. Signature photos are images that represent the key elements of an associated theme. For example, Figures 2a, 2b, and $2 \mathrm{c}$ show a collection of signature photos for themes of golfing with a grandchild, conversing about arthritis, and talking about a grandchild, respectively. By selecting one signature photo to correspond with each theme, the person with aphasia can rely on his or her relatively intact visuocognitive skills and episodic memory about specific events to identify and select topics of conversation. Then, by activating, that is, by touching or selecting a signature photo, the person can navigate to pages that contain additional information about that theme. Crucial to this navigation strategy, however, is the fact that the signature photos and their locations do not change as the visual scene system is navigated (Beukelman et al., 2007; Dietz et al., 2005).

\section{Accessing Additional Content}

After using a signature photograph to navigate to a selected theme, a person with aphasia can access additional theme content, if available, by activating an additional content button. Figure 3 shows the relative positions of signature photos used for navigation, content associated with a selected theme (in this case, carving a pumpkin with a grandchild), and the additional content button on an AAC system (Dynavox Maestro ${ }^{1}$ ) incorporating VSDs. The additional content buttons provide access to related content (i.e., photographs, written words, and speak buttons) associated with a given theme. Again, the consistency of the signature photographs allows a person to move elsewhere in the system by simply activating the appropriate signature photo in the theme display. This remains true regardless of how deep within a particular theme a person has 
(a)

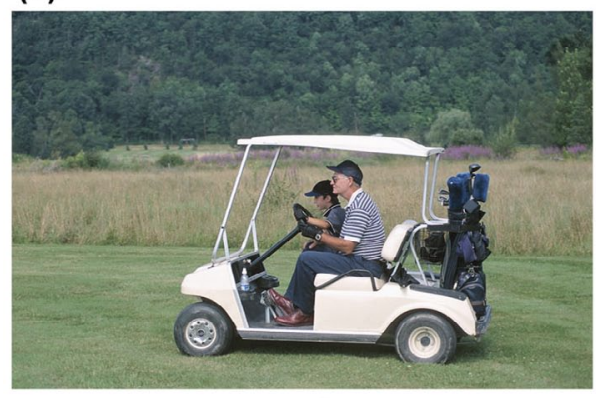

(c) (b)

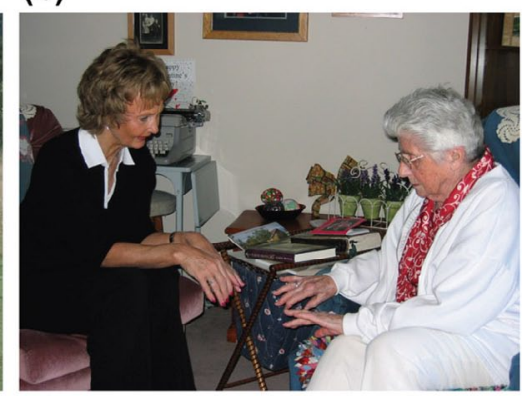

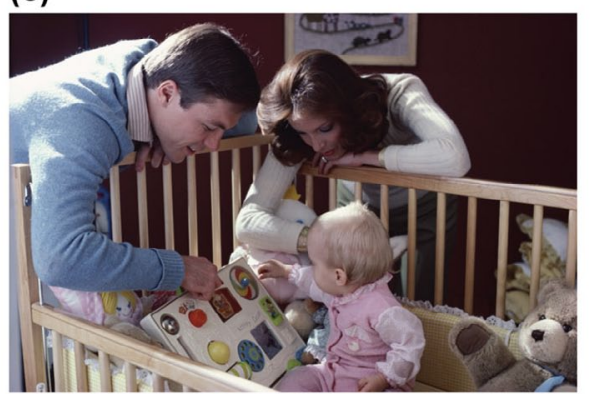

Figure 2. (a) Signature photograph of man and a boy in a golf cart. (b) Signature photograph of two women discussing their hand arthritis. (c) Signature photograph of a man and woman playing with a baby.

navigated (Beukelman et al., 2007; Dietz et al., 2005). There is a need for future research to investigate the best layout and position of the navigation bar for people with aphasia.

Thoughtfully crafted navigation strategies for low-tech AAC systems are also important for people with severe aphasia. Because of their difficulty organizing semantic information into linguistically-based (i.e., nouns, verbs, adjectives, etc.) or hierarchically based (i.e., superordinate, ordinate, and subordinate) categories (see discussion above), people with severe aphasia often struggle to locate information stored in multiple-page communication books. A strategy consistent with the theme navigation on hightech AAC devices can address this challenge. Specifically, signature photographs representing themes can serve as double-sided tabs (i.e., tabs with the same photograph appearing on both sides) to facilitate navigation. Placement of tabs so that all are visible regardless of what page is currently open in a communication book simplifies the process of navigating through multiple pages (Weissling \& Beukelman, 2006).

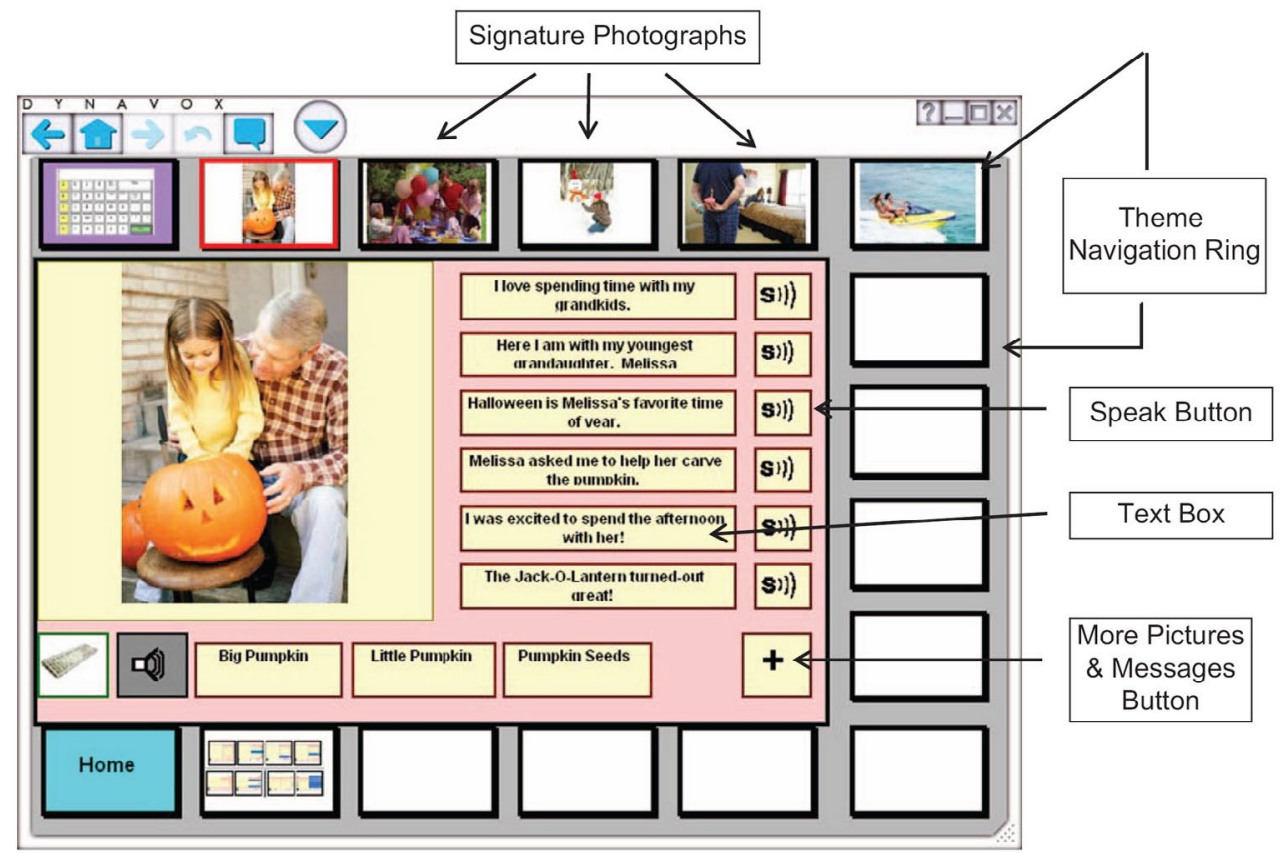

Figure 3. Visual scene display illustrating signature photographs, the theme navigation ring, speak buttons, and text box. 


\section{Technical Advances Supporting Content Selection and Management}

People with severe aphasia typically cannot manage the responsibilities associated with selecting, capturing, organizing, entering, and updating content in their visual scene systems given their symbolic processing limitations. Likewise, we have repeatedly observed that family members and friends struggle to capture or select effective high-context photographs for incorporation into VSDs for people with aphasia. This is because typically speaking communication partners often select photographs that do not include relevant people, or, if people are depicted, they are engaged with the camera rather than with objects or other people within the scene. Engebretsen, Hartman, Beukelman, and Hux (2014) confirmed this through a preliminary investigation examining the role photographs play in the communicative interactions of younger (i.e., 23-25 years) and older (i.e., 61-74 years) adults without communication challenges. Seventy-five percent of photographs self-selected by older adults to foster conversational interactions did not depict people, and $20 \%$ did not depict a background context. Furthermore, of the photographs depicting people in natural surroundings, $75 \%$ showed them engaged with the camera rather than the context. In contrast, all photographs selected by younger adults depicted people, and $55 \%$ showed people engaged with the context. Given that many communication partners of people with chronic aphasia are older rather than younger adults, providing instruction about capturing and selecting scenes that optimally support communication appears necessary. In particular, communication partners need to receive instruction about creating or finding high-context photographs in which a depicted person engages with other objects or people in the scene.

The capability of capturing, storing, displaying, and sharing images efficiently using mobile technology such as cell phones and tablets has led to substantial increases in the use of visual images to support communication interactions (Beukelman, Taylor, \& Ullman, 2013; McNaughton \& Light, 2013). About $75 \%$ of the world's population now has access to mobile technology, and it is used by people without disabilities as well as those with complex communication needs due to various acquired or developmental challenges (McNaughton \& Light, 2013). In addition to images that are personally acquired by people with aphasia and their communication partners, images from the Internet and photographs transferred by others at a distance can easily be displayed on generic smart phones and tablets. These commonplace technologies can be used in addition to specialized technologies designed explicitly to support the communication needs of people with aphasia.

Numerous technical advances have emerged within the past few years that facilitate the incorporation of VSDs into AAC devices and mobile technology (e.g., tablet, phone) applications. Previously, people had to upload photos from digital cameras to computers, then transfer them from a computer to an AAC device, and finally enter them into communication grid displays to support message representation. Over time, AAC devices were re-designed to include cameras so that people could efficiently capture and display photographic images into communication displays. Recent developments in AAC devices, as well as apps for mobile technology, now support both navigation and message representation strategies of AAC devices using images captured with built-in cameras, downloaded from the Internet, or transferred from images stored in the device. These images can be displayed or optimized in various sizes and linked to related photographic, iconic, and print content to form VSDs. Tabletbased devices are relatively lightweight and can be easily carried in one hand by people with aphasia or their communication partners. Such technical advances are encouraging for people with aphasia and those who support their communication needs; technologies now have the capability to support a range of visual image-based communication strategies developed by the aphasia research and clinical communities.

\section{Future Research Directions}

Researchers have considerable work ahead with regard to the development, refinement, and implementation of VSDs as communication supports for people with aphasia. In particular, they need to determine the kinds of treatment-induced language changes that result when formal intervention procedures incorporate high-context photographs and related textual materials as supports to everyday communicative interactions. These changes may differ substantially dependent on the type or severity of aphasia exhibited. For example, incorporating VSDs into interventions for people with mild or moderate aphasia who still talk the majority of the time may affect the quality and quantity of their expressive communication attempts to a greater extent than occurs for people with more severe forms of aphasia. Or, the early introduction of VSDs to people with aphasia may foster greater recovery of expressive and receptive language skills than typically occurs with traditional restoration-based interventions. Without further research, however, these notions are mere conjectures and lack any formal support.

Given the large number of adults who experience aphasia as a life-long condition following cerebrovascular accidents, another important area of future investigation concerns the effects of VSDs on the communicative interactions of people with chronic aphasia. Systematic investigation of specific VSD features is likely to advance our understanding of ways to best support communication occurring in a variety of settings and with unfamiliar as well as familiar partners. This includes studies addressing topics such as the incorporation of personally relevant versus generic 
photographs; the type and amount of included text; the optimal quantity of VSD content for inclusion in high- and low-technology communication supports; and the use of color-coding or other layout features to address specific pragmatic, language, or cognitive challenges.

Finally, much of the research reported in this article has focused on message representation rather than navigation within an AAC display structure. Navigation is difficult for people with severe language and cognitive limitations, and future research needs to focus on the relative effect VSD features have on navigation accuracy and efficiency by people with acquired language disorders.

\section{Conclusion}

Photographic supplementation of communication is expanding rapidly for typical speakers without complex communication needs as well as for those with speech and language limitations due to acquired aphasia. Mobile technology with built-in cameras and the capability to transfer images to other devices using a variety of strategies provides remarkable opportunities to create shared communication spaces through the construction of VSDs. Although researchers have begun to explore such VSDs as communication supports for people with aphasia, considerable work remains to refine their development, application, and implementation across a variety of communication settings. Related research is needed to address the type of instruction needed to assist communication partners, who typically do not experience speech or language challenges, to select appropriate photographs for supporting the communication of people with various types and severities of aphasia. Finally, although the focus of this article was on people with sudden-onset aphasia due to cerebrovascular accidents, many individuals with complex communication needs due to other types of language or cognitive-communication impairments may benefit from advances in the use of VSDs as communication supports.

\section{Note}

1. Dynavox Maestro, Tobii-Dynavox, Pittsburgh, PA.

Acknowledgments - The authors thank the people with chronic, severe aphasia, their families, and caregivers who served as participants in our research program. We also appreciate the ongoing advice and encouragement that we received from our partners in the RERC for AAC. The authors report no conflicts of interests. The authors alone are responsible for the content and writing of this paper. This publication was produced in part under Grants H113980026 and H133E140026 from the National Institute on Disability and Rehabilitation Research (NIDRR) The opinions expressed in this publication are those of the grantee and do not necessarily reflect those of NIDRR or the Department of Education.

\section{References}

Beukelman, D. R., Dietz, A., Hux, K., McKelvey, M., \& Weissling, K. (2007). Training module: Visual scene displays. Pittsburgh, PA: DynaVox Technologies.

Beukelman, D. R., \& Garrett, K. (1988). Augmentative and alternative communication for adults with acquired severe communication disorders. Augmentative and Alternative Communication, 4, 104-121.

Beukelman, D. R., Taylor, S., \& Ullman, C. (2013). Digital image capture and management. In N. Simons-Mackie, J. King, \& D.

Beukelman, eds., Communication support for people with aphasia (pp. 325334). Baltimore, MD: Paul H. Brookes.

Beukelman, D. R., Yorkston, K., \& Dowden, P. (1985). Augmentative communication: A casebook of clinical management. San Diego, CA: College Hill Press.

Blake, M. (2005). Right hemisphere syndrome. In L. LaPointe, ed., Aphasia and related neurogenic language disorders (pp. 213-224). New York, NY: Thieme Medical.

Brennan, A., Worrall, L., \& McKenna, K. (2005). The relationship between specific features of aphasia-friendly written material and comprehension of material for people with aphasia: An exploratory study. Aphasiology, 19, 693-711.

Brookshire, R. H. (1978). An introduction to aphasia (2nd ed.). Minneapolis, MN: BRK Publishers.

Brookshire, R. H. (2003). Introduction to neurogenic communication disorders (5th ed.). St. Louis, MO: Mosby.

Chapey, R. (2001). Cognitive stimulation: Stimulation of recognition/ comprehension, memory and convergent, divergent, and evaluative thinking. In R. Chapey, ed., Language intervention strategies in aphasia and related neurogenic communication disorders (4th ed., pp. 397-434). Baltimore, MD: Lippincott, Williams, and Wilkins.

Collins, M. (1986). Diagnosis and treatment of global aphasia. San Diego, CA: College-Hill Press.

Darley, F. L. (1982). Aphasia. Philadelphia, PA: WB Saunders Company.

Dietz, A., Hux, K., McKelvey, M., \& Beukelman, D. (2009 ). Reading comprehension by people with chronic aphasia: A comparison of three levels of visuographic contextual support. Aphasiology, 23, 10531064. doi:10.1080/02687030802635832

Dietz, A., Knollman-Porter, K., Hux, K., Toth, K., \& Brown, B. (2014). Supported reading comprehension for people with aphasia: Photographic and linguistic pre-reading supports. Journal of Medical Speech-Language Pathology, 21, 319-331.

Dietz, A., McKelvey, M., \& Beukelman, D. R. (2006). Visual scene display (VSD): New AAC interfaces for persons with aphasia. Perspectives on Augmentative and Alternative Communication, 15, 13-17.

Dietz, A., McKelvey, M., Beukelman, D. R., Weissling, K., \& Hux, K. (2005). Visual scenes display: A new AAC interface for persons with severe chronic aphasia. Paper presented at the American Speech-Language and Hearing Association Annual National Convention, San Diego, CA.

Dietz, A., Weissling, K., Griffith, J., McKelvey, M., \& Macke, D. (2014). The impact of interface design during an initial high-technology AAC experience: A collective case study of people with aphasia. Augmentative and Alternative Communication, 30, 314-328.

Duffy, J. R., \& Coelho, C. A. (2001). Schuell's stimulation approach to rehabilitation. In R. Chapey, ed., Language intervention strategies in aphasia and related neurogenic communication disorders (4th ed., pp. 341-382 ). Baltimore, MD: Lippincott, Williams, and Wilkins. 
Dukhovny, E., \& Soto, G. (2013). Speech generating devices and modality of short-term word storage. Augmentative and Alternative Communication, 29, 246-258.

Engebretsen, K., Hartman, R., Beukelman, D., \& Hux, K. (2014). The role photographic images in face-to-face human interaction by younger and older adults. Perspectives on Augmentative and Alternative Communication, 23, 82-89.

Fox, L. E., \& Fried-Oken, M. (1996). AAC aphasiology: Partnership for future research. Augmentative and Alternative Communication, 2, $38-44$.

Garrett, K. (1993). Changes in the conversational participation of individuals with severe aphasia given three types of partner support. Dissertation Abstracts International, 54, 5113.

Garrett, K., Beukelman, D., \& Low-Morrow, D. (1989). A comprehensive augmentative communication system for an adult with Broca's aphasia. Augmentative and Alternative Communication, 5, 55-61.

Garrett, K., \& Huth, C. (2002). The impact of graphic contextual information and instruction on the conversational behaviors of a person with severe aphasia. Aphasiology, 16, 523-536.

Garrett, K., \& Lasker, J. (2005). Adults with severe aphasia. In D. BeukeIman \& P. Mirenda, eds., Augmentative and alternative communication (3rd ed., pp. 467-504 ). Baltimore, MD: Paul H. Brooks.

Garrett, K., \& Lasker, J. (2013). Adults with severe aphasia and apraxia of speech. In D. Beukelman \& P. Mirenda, eds., Augmentative and alternative communication: Supporting children and adults with complex communication needs (4th ed., pp. 405-446 ). Baltimore, MD: Paul H. Brookes.

Goodglass, H., \& Blumstein, S. (1973). Psycholinguistics and aphasia. Baltimore, MD: Johns Hopkins University Press.

Griffith, J., Dietz, A., \& Weissling, K. (2014). Supported narrative retells for people with aphasia using augmentative and alternative communication: Photographs or line drawings? Text or no text? American Journal of Speech-Language Pathology, 23, S213-S224.

Helm-Estabrooks, N. (1984). Severe aphasia. In A. Holland, ed., Language disorders in adults (pp. 159-176 ). San Diego, CA: College Hill Press.

Hinckley, J., Douglas, N., Goff, R., \& Nakano, E. (2013). Supporting communication with partner training. In N. Simons-Mackie, J. King, \& D. Beukelman, eds., Communication support for people with aphasia (pp. 245-274). Baltimore, MD. Paul H. Brookes.

Ho, K., Weiss, S., Garrett, K., \& Lloyd, L. (2005). The effect of remnant and pictographic books on the communicative interaction of individuals with global aphasia. Augmentative and Alternative Communication, 21, 218-232.

Holland, A., \& Beeson, P. (1993). Finding a new sense of self: What the clinician can do to help. A reply to Brumfitt's losing one's sense of self following stroke. Aphasiology, 7, 569-591.

Holland, A., Fromm, V., DeRuyter, F., \& Stein, M. (1996). Treatment efficacy for aphasia. Journal of Speech and Hearing Research, 39, S27-S36.

Horner, J., Loverso, F., \& Gonzalez-Rothi, L. (1994). Models of aphasia treatment. In R. Chapey, ed., Language intervention strategies in adult aphasia (3rd ed., pp. 135-145 ). Baltimore, MD: Williams and Wilkins.

Howard, D., \& Hatfield, F. (1987). Aphasia therapy: Historical and contemporary issues. London, UK: Lawrence Erlbaum Associates.

Hux, K., Buechter, M., Wallace, S., \& Weissling, K. (2010). Using visual scene displays to create a shared communication space for a person with aphasia. Aphasiology, 24, 643-660.

Hux, K., Weissling, K., \& Wallace, S. (2008). Communication-based interventions: AAC for people with aphasia. In R. Chapey, ed., Language intervention strategies in adult aphasia (5th ed., pp. $814-836$ ). Baltimore, MD: Williams \& Wilkins.

Jackson-Waite, K., Robson, J., \& Pring, T. (2003). Written communication using a LightWriter in undifferentiated jargon aphasia: A single case study. Aphasiology, 17, 767-780.

Jenkins, J., Jimenez-Pabon E., Shaw, R., \& Sefer, J. (1975). Schuell's aphasia in adults: Diagnosis, prognosis, and treatment (2nd ed.). Hagerstown, MD: Harper \& Row.

Kagan, A. (1998). Supporting conversation for adults with aphasia methods and resources for training communication partners. Aphasiology, 12, 816-830.

King, J. (2013). Communication supports. In N. Simons-Mackie, J. King, \& D. Beukelman, eds., Communication support for people with aphasia (pp. 51-72 ). Baltimore, MD: Paul H. Brookes.

King, J., \& Alarcon, N., \& Rogers, M. (2007). Primary progressive aphasia. In D. Beukelman, K. L. Garrett, \& K. Yorkston, eds., Augmentative communication strategies for adults with acute or chronic medical conditions. p. 207-242. Baltimore, MD: Brookes.

Koul, R., Corwin, M., \& Hayes, S. (2005). Production of graphic symbol sentences by individuals with aphasia: Efficacy of a computerbased augmentative and alternative communication intervention. Brain and Language, 92, 58-77.

Koul, R., Corwin, M., Nigam, R., \& Oetzel, S. (2008). Training individuals with severe Broca's aphasia to produce sentences using graphic symbols: Implications for AAC intervention. Journal of Assistive Technologies, 2, 23-34.

Koul, R., \& Harding, R. (1998). Identification and production of graphic symbols by individuals with aphasia: Efficacy of a software application. Augmentative and Alternative Communication, 14, 11-23.

Koul, R., \& Lloyd, L. (1998). Comparison of graphic symbol learning in individuals with aphasia and right hemisphere brain damage. Brain and Language, 62, 398-421.

LaPointe, L. (2005). Foundations, adaptations, and accommodations, Aristos. In L. LaPointe, ed., Aphasia and related neurogenic language disorders (pp. 1-18 ). New York, NY: Thieme Medical.

LaPointe, L. (2011). Humanistic basics: Adaptation, accommodation, and aristos. In L. L. LaPoint, ed., Aphasia and related neurogenic language disorders (4th ed., pp. 9-26 ). New York, NY: Thieme.

Laska, A. C., Hellblom, A., Murray, V., Kahan, T., \& Von Arbin, M. (2001). Aphasia in acute stroke and relation to outcome. Journal of Internal Medicine, 249, 413-422.

Lasker, J. (1999). Peers' perception of storytelling by an adult with aphasia. Aphasiology, 13, 857-869.

Lasker, J., \& Bedrosian, J. (2001). Promoting acceptance of AAC by adults with acquired communication disorders. Augmentative and Alternative Communication, 17, 141-153.

Lasker, J., \& Beukelman, D. (1999). Peers' perceptions of storytelling by an adult with aphasia. Aphasiology, 13, 857-869.

Lasker, J., Garrett, K., \& Fox, L. (2007). Severe aphasia. In D. Beukelman, K. Garrett, \& K. Yorkston, eds., Augmentative communication strategies for adults with acute or chronic medical conditions (pp. 163-206). Baltimore, MD: Paul H. Brookes.

Lasker, J., LaPointe, L., \& Kodras, J. (2005). Helping a professor with aphasia resume teaching through multimodal approaches. Aphasiology, 19, 399-410.

Light, J., \& McNaughton, D. (2013). Putting people first: Re-thinking the role of technology in augmentative and alternative communication intervention. Augmentative and Alternative Communication, 29, 299-309. 
Lyon, J. (1992). Communication use and participation in life for adults with aphasia in natural settings: The scope of the problem. American Journal of Speech-Language Pathology, 1, 7-14.

Lyon, J. (1995). Drawing: Its value as a communication aid for adults with aphasia. Aphasiology, 9, 33-49.

Lyon, J. (1998). Treating "the whole" of aphasia. Paper presented at the Annual Spring Rehabilitation Conference, Lincoln, NE.

Lyon, J., \& Helm-Estabrooks, N. (1987). Drawing: Its communicative significance for expressively restricted adults. Topics in Language Disorders, 8, 61-71.

McKelvey, M., Dietz, A., Hux, K., Weissling, K., \& Beukelman, D. (2007). Performance of a person with chronic aphasia using a visual scene display prototype. Journal of Medical Speech Language Pathology, 15, 305-317.

McKelvey, M., Hux, K., Dietz, A., \& Beukelman, D. (2010). Impact of personal relevance and contextualization on comprehension by people with chronic aphasia. American Journal of Speech Language Pathology, 19, 22-33.

McNaughton, D., \& Light, J. (2013). The iPad and mobile technology revolution: Benefits and challenges for individuals who require augmentative and alternative communication. Augmentative and Alternative Communication, 29, 107-116.

McNeil, M. (1983). Aphasia: Neurological considerations. Topics in Language Disorders, 3, 1-19.

Murray, L. (1999). Attention and aphasia: Theory, research and clinical implications. Aphasiology, 13, 91-111.

Pedersen, P., Vinter, K., \& Olsen, T. (2004). Aphasia after stroke: Type, severity, and prognosis. The Copenhagen aphasia study. Cerebrovascular Diseases, 17, 35-43.

Poeck, K., Huber, W., \& Williams, K. (1989). Outcome of intensive language treatment in aphasia. Journal of Speech and Hearing Disorders, 54, 471-479.

Robey, R. (1998). A meta-analysis of clinical outcomes in the treatment of aphasia. Journal of Speech, Language, and Hearing Research, 41, 172-187.

Scott, J., \& Schoenberg, M. (2011). Memory and learning: The forgetful patient. In M. Schoenberg \& J. Scott, eds., The little black book of neuropsychology: A syndrome-based approach (pp. 179-200). New York, NY: Springer.

Schoenberg, M., Marsh, P., \& Lerner, A. (2011). Neuroanatomy primer: Structure and function of the human nervous system. In M. R. Schoenberg \& J. G. Scott, eds., The little black book of neuropsychology: A syndrome-based approach (pp. 59-126). New York, NY: Springer.

Schuell, H., Jenkins, J., \& Jimenez-Pabon, E. (1964). Aphasia in adults. New York, NY: Harper \& Row, Hoeber Medical Division.

Simmons-Mackie, N., King, J., \& Beukelman, D. (2013). Supporting communication for adults with acute and chronic aphasia. Baltimore, MD: Paul H. Brookes.

Simmons-Mackie, N., \& Schultz, M. (2004). "Speaking for another": Management of participant frames in aphasia. American Journal of SpeechLanguage Pathology, 18, 114-127.
Stuart, S., Lasker, J., \& Beukelman, D. (2000). AAC message management. In D. Beukelman, K. Yorkston, \& J. Reichle, eds., Augmentative communication for adults with neurologic disorders (pp. 25-54). Baltimore, MD: Paul H. Brookes.

Thiessen, A. (2013). Visual attention patterns for contextually rich images: Neurotypical adults in two age groups and adults with aphasia. Retrieved from ETD collection for University of Nebraska-Lincoln. (AAI3558630).

Thiessen, A., Beukelman, D., Ullman, C., \& Longenecker, M. (2014). Measurement of the visual attention patterns of people with aphasia: A preliminary investigation of two types of human engagement in photographic images. Augmentative and Alternative Communication, 30, 120-129.

Thistle, J., \& Wilkinson, K. M. (2013). Working memory demands of aided augmentative and alternative communication for individuals with developmental disabilities. Augmentative and Alternative Communication, 29, 235-245.

Van de Sandt-Koenderman, M. (2004). High-tech AAC and aphasia: Widening horizons? Aphasiology, 18, 245-263.

Wallace, S., Dietz, A., Hux, K., \& Weissling, K. (2012). Augmented input: The effect of visuographic supports on the auditory comprehension of people with chronic aphasia. Aphasiology, 26, 162-176.

Wallace, S., Hux, K., Brown, J., \& Knollman-Porter, K. (2014). High-context images: Comprehension of main, background, and inferential information by people with aphasia. Aphasiology, 28, 713-730.

Weissling, K., \& Beukelman, D. (2006). Visual scene displays: Low-tech options. Perspective on Augmentative and Alternative Communication, 15, 15-17.

Weissling, K., \& Prentice, C. (2010). The timing of remediation and compensation rehabilitation programs for individuals with acquired brain injuries: Opening the conversation. Perspectives on Augmentative and Alternative Communication, 19, 87-96.

Wilkinson, K., \& Jagaroo, V. (2004). Contributions of principles of visual cognitive science to AAC system display design. Augmentative and Alternative Communication, 20, 123-136.

Wilkinson, K., \& Light, J. (2011). Preliminary investigation of visual attention to human figures in photographs: Potential considerations for the design of aided AAC visual scene displays. Journal of Speech, Language, and Hearing Research, 54, 1644-1657.

Wilkinson, K., Light, J., \& Drager, K. (2012). Considerations for the composition of visual scene displays: Potential contributions of information from visual and cognitive sciences. Augmentative and Alternative Communication, 28, 137-147.

Wilkinson, K., \& Snell, J. (2011). Facilitating children's ability to distinguish symbols for emotions: The effects of background color cues and spatial arrangement of symbols on accuracy and speed of search. American Journal of Speech-Language Pathology, 20, 288-301.

Wright, H., Downey, R., Gravier, M., Love, T., \& Shapiro, L. (2007). Processing distinct linguistic information types in working memory in aphasia. Aphasiology, 21, 802-813. 